\title{
A Study on Antioxidant Activity of Hyptis suaveolens (L) poit
}

\author{
P. Mozhiyarasi* and R. Anuradha \\ Department of Biochemistry, S.T.E.T Women's College, Mannargudi, \\ Tamilnadu-614 001, India \\ *Corresponding author
}

A B S T R A C T

\begin{tabular}{|l|}
\hline Ke y w o r d s \\
$\begin{array}{l}\text { Hyptis Suaveolens }(\mathrm{L}) \\
\text { poit, Antioxidant activity, } \\
\text { Free radical scavenging } \\
\text { activity }\end{array}$ \\
\hline Article Info \\
\hline $\begin{array}{l}\text { Accepted: } \\
\text { 02 May 2018 } \\
\text { Available Online: } \\
\text { 10 June } 2018\end{array}$ \\
\hline
\end{tabular}

\section{Introduction}

The role of free radical reactions in disease pathology is well established and is known to be involved in many acute and chronic disorders in human beings, such as diabetes, atherosclerosis, aging, immuno suppression and neuro degeneration. An imbalance between ROS and the inherent antioxidant capacity of the body, directed the use of dietary and /or medicinal supplements particularly during the disease attack. The ingestion of natural antioxidants has been inversely associated with morbidity and mortality from degenerative disorders (Halliwell et al., 1981). Antioxidant agents of natural origin have attracted special interest because of their free radical scavenging abilities (Osawa et al., 1990). The use of medicinal plants with high level of antioxidant constituents has been proposed as an effective therapeutic approach for free radical mediated diseases (Govind et al., 2011).

Hyptis suaveolens is a very common plant in India. Indians used to call it "Chan/Wilaiti tulsi" and the morning soup made by mixing it with corn is called "Bate" meaning memory aid. Tea made from the roots of $H$. suaveolens is used to purify the blood, and it is also used as a remedy for the "diseases" of women (Fig. 1). It has been used as a medicinal tea in many places in Asia (Palmer, 1891) and as a food and source of essential oil in South America (Gentry et al., 1990). The plant Hyptis suaveolens (L.) Poit; (Lamiaceae) is reported 
to possess antifertility (Garg, 1976), Antimicrobial (Okonogi et al., 2005), Anthelmintic (Oliver, 1960), Immunomodulatory activity (Bhagwat, 2003) and antiplasmodial properties (Ziegler et al., 2002; Chukwujekwu et al., 2005). Hyptis suaveolens is an important source of essential oils, alkaloids, flavonoids, phenols, saponins, terpenes, and sterol, tannins. The present study was carried out to evaluate the Antioxidant activity of Aqueous, Ethanol, Methanol, Diethyl ether, Chloroform extract of Hyptis suaveolens $(L$.) poit using various methods

\section{Materials and Methods}

\section{Collection of plant materials}

Fresh leaves of Hyptis suaveolens (L.) Poit were collected from Kannukudi, Thanjavur (DT), Tamilnadu, India. They were identified by Dr. S. John britto, The Director, The Rapinet herbarium St. Joseph's college, Thiruchirapalli and voucher specimens were deposited in the Rapinet herbarium of St. Joseph's College, Thiruchirapalli (Voucher number K G 001/ 2013).

\section{Extraction of plant material}

The leaves of plants were dried under shade. The dried materials were mechanically powdered sieved using 80 meshes and stored in an air tight container. The powdered material was used for further photochemical, and antimicrobial activity. Aqueous, Methanol, Diethyl ether, Chloroform and ethanol extracts were prepared according to the methodology of Indian pharmacopoeia. The coarse powder material was subjected to soxhlet extraction separately and successively with ethanol and distilled water, methanol, Diethyl ether, chloroform, these extracts were concentrated to dryness in flash evaporator under reduced pressure and controlled temperature $\left(40^{\circ} \mathrm{c}\right.$ to $\left.50^{\circ} \mathrm{C}\right)$ the aqueous and ethanol extracts put in air tight container stored in a refrigerator

\section{Antioxidant activity}

\section{DPPH radical scavenging activity}

For DPPH radical scavenging activity, Stock solutions of extracts was prepared to the concentration of $1 \mathrm{mg} / \mathrm{ml} .1 \mathrm{ml}$ of each extract were added at an equal volume to methanol solution of DPPH $(0.1 \mathrm{mM})$. All the reaction mixture is incubated for $30 \mathrm{~min}$ at room temperature. The absorbance was recorded at $517 \mathrm{~nm}$. Ascorbic acid was used as standard (Blois, 1958).

\section{Total antioxidant activity}

Total antioxidant activity of plant extract was determined by dissolving $1 \mathrm{ml}$ of the all extracts of plant in water and mixed with $3 \mathrm{ml}$ of reagent solution $(0.6 \mathrm{M}$ sulfuric acid, $28 \mathrm{mM}$ sodium phosphate and $4 \mathrm{mM}$ ammonium molybdate) in Eppendorf tube. The tubes were capped and incubated in a thermal block at $95^{\circ} \mathrm{C}$ for $90 \mathrm{~min}$. After $90 \mathrm{~min}$, the mixtures were cooled at room temperature; the absorbance was measured at $695 \mathrm{~nm}$ against reagent blank. Ascorbic acid was used as the standard and the total antioxidant capacity is expressed as equivalents of ascorbic acid (Kumaran and Karunakaran, 2007).

\section{Nitric oxide radical scavenging activity}

Nitric oxide radical scavenging activity of plant drug was measured by mixing Sodium nitro prusside $(1 \mathrm{ml}$ of $10 \mathrm{Mm})$ with $1 \mathrm{ml}$ of plant drug of different extracts in phosphate buffer ( $\mathrm{pH}$ 7.4). The mixtures were incubated at $25^{\circ} \mathrm{C}$ for $150 \mathrm{~min}$. To $1 \mathrm{ml}$ of the incubated solution, $1 \mathrm{ml}$ of Griess' reagent (1\% sulphnilamide, $2 \%$ o-phosphoric acid and $0.1 \%$ naphthyl ethylene diamine hydrochloride) was added. Ascorbic acid was 
used as the standard. Absorbance was read at $546 \mathrm{~nm}$ and percentage inhibition was calculated (Streejayan et al., 1997).

\section{Hydrogen peroxide scavenging activity}

In Hydrogen peroxide radical scavenging activity a solution of $\mathrm{H}_{2} \mathrm{O}_{2}$ was prepared in phosphate buffer ( $\mathrm{pH}$ 7.4). $\mathrm{H}_{2} \mathrm{O}_{2}$ concentration was determined spectrophotometrically by measuring absorption with extinct coefficient for $\mathrm{H}_{2} \mathrm{O}_{2}$. Various extract of plant drug in distilled water was added in $\mathrm{H}_{2} \mathrm{O}_{2}$ solution $(0.6 \mathrm{ml}, 40 \mu \mathrm{M} /)$. After $10 \mathrm{~min}$, absorbance of $\mathrm{H}_{2} \mathrm{O}_{2}$ was measured at $230 \mathrm{~nm}$ against blank solution containing the phosphate buffer without $\mathrm{H}_{2} \mathrm{O}_{2}$. The percentage of scavenging effect of plant and standard ascorbic acid were calculated (Ruch et al., 1989).

\section{Reducing power assay}

Reducing ability of plant drug was measured by the method of Yildirim et al., (2001). To $1.0 \mathrm{ml}$ extract) added $2.5 \mathrm{ml}$ of phosphate buffer $(0.2 \mathrm{~m}, \mathrm{pH} 6.6)$ and $2.5 \mathrm{ml}$ of $1 \%$ potassium ferricyanide and incubated at $50^{\circ} \mathrm{C}$ for $30 \mathrm{~min}$. After that $2.5 \mathrm{ml}$ of trichloro acetic acid $(10 \%)$ were added to the mixture and centrifuged for $10 \mathrm{~min}$ at $3000 \mathrm{xg}$. $2.5 \mathrm{ml}$ from the upper part were diluted with $2.5 \mathrm{ml}$ water and shaken with $0.5 \mathrm{ml}$ fresh $0.1 \%$ ferric chloride. Ascorbic acid was used as the standard. The absorbance was measured at 700nm using UV- spectrophotometer.

\section{Results and Discussion}

The study investigated that the antioxidant activity of aqueous, ethanol diethyl ether and ethanol extract of Hyptis suaveolens (L) poit. The aqueous, ethanolic, methanolic and diethyl ether extract of Hyptis suaveolens were tested for antioxidant activity ion different in vitro models. Experiments were carried out in triplet form to calculate mean and standard deviation. The percentage of inhibition in various models viz. DPPH radical scavenging activity (\%), Total antioxidant capacity, Nitric oxide radical scavenging activity (\%), Hydrogen peroxide scavenging activity (\%) Reducing power assay (\%) was represented as mean \pm standard error in table 1 .

\section{DPPH radical scavenging activity}

DPPH radical scavenging activity of aqueous, ethanol, methanol and diethyl ether extract of Hyptis suaveolens represented in table 1. The diethyl ether extract showed 55.2 $\pm 0.56 \%$, Chloroform extract showed $31.5 \pm 0.5 \%$, whereas the methanolic extract showed $50.5 \pm 0.5 \%$ and aqueous extract having least total antioxidant potential of $30.3 \pm 0.5 \%$. The ethanolic extract having greater antioxidant capacity $(60.4 \pm 0.4)$ which was nearer to the value showed by vitamin $\mathrm{C}(65.5 \pm 0.5)$. DPPH assay is a good method for evaluating the antioxidant efficacy. This assay provided useful information on the reactivity of the test compounds with stable free radicals. The DPPH relatively stable free radicals and the test determine the capacity of the test material to reduce the DPPH radicals to the corresponding hydrazine. The inhibition of DPPH radical showed that Hyptis suaveolens cause reduction of DPPH radical in spectrometric manner.

DPPH is a stable free radical accepts an electron or hydrogen radical to become stable diamagnetic molecules. The reduction capability of the DPPH radical is determined by the decrease in its absorbance at $517 \mathrm{~nm}$ induced by antioxidants. The decrease in absorbance DPPH radical caused by antioxidant because of the reaction between antioxidant molecules and radical donation. Hence DPPH is usually used as a substrate to evaluate the antioxidant activity of antioxidant. 
Fig.1 Pictorial representation of Hyptis suaveolens (L.) Poit

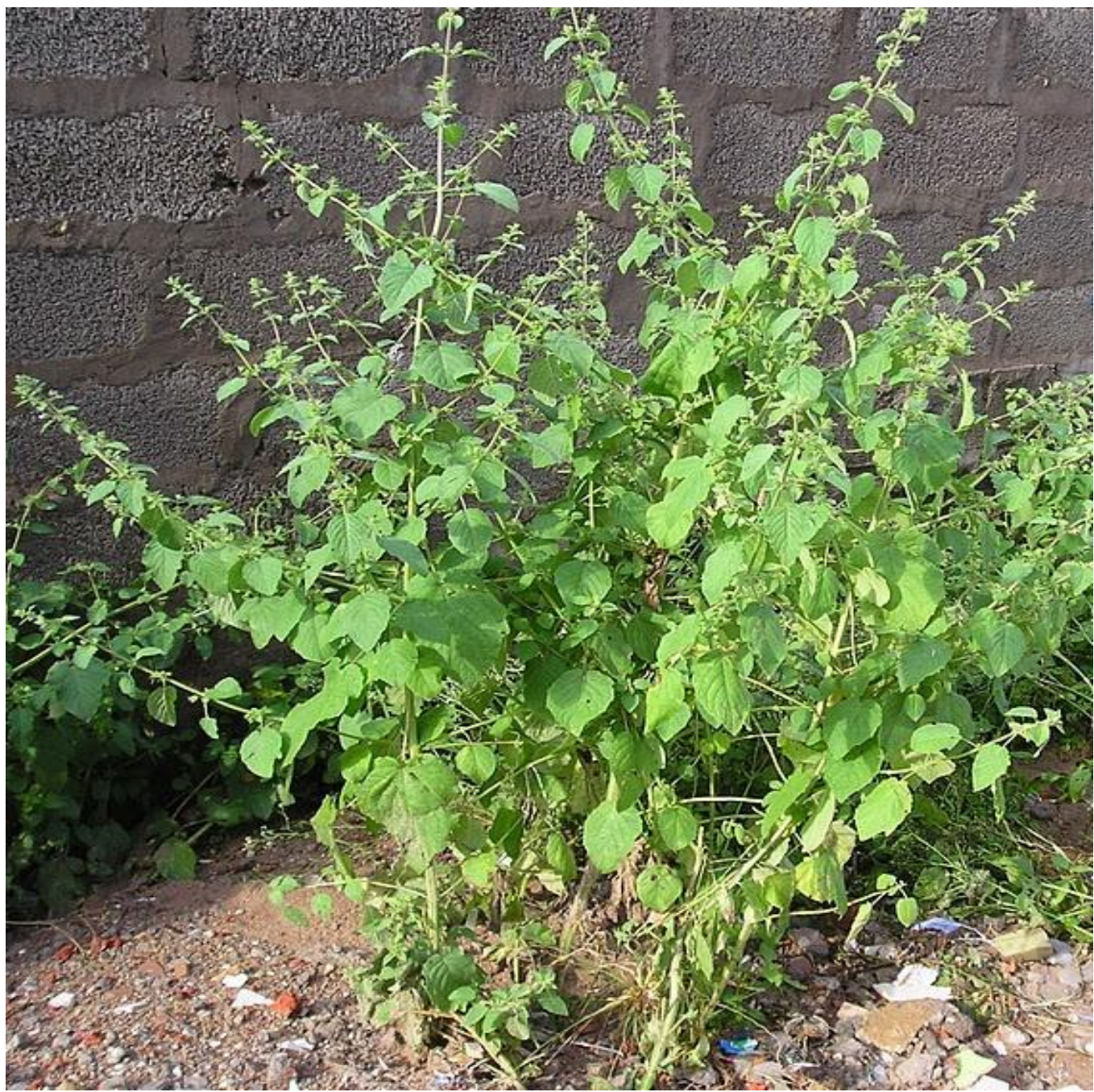

Table.1 Antioxidant activity of various extracts of leaf of Hyptis suaveolens Linn (poit)

\begin{tabular}{|c|c|c|c|c|c|c|c|}
\hline \multirow{2}{*}{$\begin{array}{l}\text { S. } \\
\text { No }\end{array}$} & \multirow[t]{2}{*}{ Particulars } & \multicolumn{6}{|c|}{ Plant Extracts } \\
\hline & & Aqueous & Ethanol & Methanol & Diethyl ether & chloroform & Vit C \\
\hline 1 & $\begin{array}{l}\text { DPPH radical scavenging } \\
\text { activity }(\%)\end{array}$ & $30.3 \pm 0.5$ & $60.4 \pm 0.4$ & $50.5 \pm 0.5$ & $55.2 \pm 0.56$ & $31.5 \pm 0.5$ & $65.5 \pm 0.5$ \\
\hline 2 & Antioxidant activity (\%) & $33.5 \pm 0.4$ & $65.4 \pm 0.5$ & $55.2 \pm 0.5$ & $40.2 \pm 0.2$ & $35.5 \pm 0.4$ & $70.5 \pm 0.5$ \\
\hline 3 & $\begin{array}{l}\text { Nitric oxide radical } \\
\text { scavenging activity }(\%)\end{array}$ & $32.2 \pm 0.3$ & $55.4 \pm 0.3$ & $40.2 \pm 0.6$ & $38.5 \pm 0.4$ & $31.0 \pm 0.5$ & $60.5 \pm 0.4$ \\
\hline 4 & $\begin{array}{l}\text { Hydrogen peroxide } \\
\text { scavenging activity (\%) }\end{array}$ & $36.4 \pm 0.4$ & $50.4 \pm 0.5$ & $42.5 \pm 0.5$ & $35.4 \pm 0.5$ & $30.5 \pm 0.2$ & $60.0 \pm 0.5$ \\
\hline 5 & $\begin{array}{l}\text { Reducing power assay } \\
(\%)\end{array}$ & $28.5 \pm 0.2$ & $60.5 \pm 0.5$ & $45.3 \pm 0.4$ & $40.5 \pm 0.5$ & $25.8 \pm 0.5$ & $65.0 \pm 0.5$ \\
\hline
\end{tabular}




\section{Total antioxidant activity}

The total antioxidant activity of various extract Hyptis suaveolens (L) poit. Was depicted in table 1 . Scavenging activity of aqueous extract was found to be $33.5 \pm 0.4 \%$ whereas ethanolic extract showed the maximum scavenging activity such as $65.4 \pm 0.5 \%$. Scavenging activity of methanolic and diethyl ether extract were found as $55.2 \pm 0.5 \%, \quad 40.2 \pm 0.2 \% \quad$ respectively. Chloroform extract showed $35.5 \pm 0.4 \%$ among five extract, ethanolic extract showed greater potentiality which was nearer to the value showed by vitamin $C(70.5 \pm 0.5 \%)$.

The total antioxidant capacity of the extract was calculated based on the formation of phosphomolybdenum complex which was measured at spectrometrically at $695 \mathrm{~nm}$. The total antioxidant capacity of the extract of Hyptis suaveolens, was greater when compared to aqueous, Methanol, Diethyl ether, extracts. The total antioxidant capacity may be due to antioxidant principle in the extract.

\section{Nitric oxide radical scavenging activity}

Nitric oxide radical scavenging activity of, aqueous, ethanolic, methanolic, Diethyl ether, Chloroform extract of Hyptis suaveolens $(L)$ poit represented in table 1. Nitric oxide radical scavenging activity of aqueous and ethanolic extract of were found to be $32.2 \pm 0.3 \%, \quad 55.4 \pm 0.3 \% \quad$ respectively. Methanolic, diethyl ether, Chloroform extracts showed $40.2 \pm 0.6 \%, \quad 38.5 \pm 0.4 \%$, $31.0 \pm 0.5 \%$ respectively. In case of vitamin C it was found to be $60.5 \pm 0.4 \%$. Nitric Oxide (NO) is an important chemical mediator generated by endothelial cells, macrophages, neurons etc and involved in the regulation of various physiological processes (Lata et al., 2003). Excess concentration of NO is associated with several diseases (Alenti, 1993 and Ross et al., 1990). Oxygen reacts with the excess nitric oxide to generate nitrite and peroxynitrate anions, which act as free radicals (Cotran et al., 1999 and Sainani et al., 1997). In the present study, the extract competes with oxygen to react with nitric oxide and thus inhibit the generation of the anions.

\section{Hydrogen peroxide scavenging activity (\%)}

Table 1 revealed the Hydrogen peroxide scavenging activity of various extract of Hyptis suaveolens (L) poit, the aqueous extract showed $36.4 \pm 0.4 \%$ Free radical scavenging activity in ethanolic extract was found to be $50.4 \pm 0.5 \%$ and in methanolic extract it was found to be $42.5 \pm 0.5$. Diethyl ether and Chloroform showed the potentiality of $35.4 \pm 0.5 \%, 30.5 \pm 0.2 \%$ respectively. From this above, it was noted that ethanolic extract showed maximum capacity comparable with Ascorbic acid $(60.0 \pm 0.5 \%)$.

\section{Reducing power assay}

Reducing power assay of aqueous, ethanolic, methanolic, Diethyl ether and Chloroform extracts showed $28.5 \pm 0.2 \%, \quad 60.5 \pm 0.5 \%$, $45.3 \pm 0.4 \%, \quad 40.5 \pm 0.5 \%, \quad 25.8 \pm 0.5 \%$ respectively. Among five extract, ethanolic extract showed greater potentiality which was nearer to the value showed by vitamin $\mathrm{C}$ $(60.5 \pm 0.5 \%)$. The reducing capacity of a compound may serve as a significant indicator of its potential antioxidant activity. The reducing ability is generally associated with the presence of reductones, which breaks the free radical chain by donating a hydrogen atom (Subhashini, 2011).

From the above, it was found to that ethanolic extract showed the highest antioxidant capacity and is a valuable source of antioxidant both for preparation of crude extracts and for further isolation and 
purification of antioxidant components. Hyptis suaveolens (L) poit found to suppress hydroxyl radical formation, through different chemical mechanisms, including free radicals quenching, electron transfer, radical addition or radical recombination in-vitro. There is good scope in examining the herb for its antioxidant and free radicals scavenging activity in vivo.

\section{Acknowledgement}

Authors acknowledge the aequate facilities provided by Dr. V. Dhivakaran, Managing Trustee, STET Women's College, Mannargudi.

\section{References}

Alenti A, Moncada S and Di Rosa M. Modulation of adjuvant arthritis by endogenous nitric oxide. $\mathrm{Br} \mathrm{J}$ Pharmacol. 1993; 110:701.

Bhagwat DP and Umathe SN. The Immunomodulatory Activity of Hyptis suaveolens (L.) Poit., Indian Journal of Pharmacology, 2003; 35: 128-36.

Blois, M.S., 1958. Antioxidant determinations by the use of a stable free radical. Nature, 29: 1199-1200.

Chadha, K.L. and Pareek, O.P. (1988). Genetic resources of fruits crops: achievements and gaps. Indian $\mathrm{J} . \mathrm{Pl}$. Genet. Resour., 1: 43-48

Chukwujekwu JC, Smith P, Coombes PH, Mulholland DA and Staden J Van. Antiplasmodial diterpenoid from the leaves of Hyptis suaveolens. Journal of Ethnopharmacology, 2005; 102(2): 2957.

Cotran R S, Kumar V and Collins $\mathrm{T}$ in Robbin's Pathological basis of diseases. 6th edn. (Thomson Press (I) Ltd, Noida, India). 1999; 1

Danmalam UH, Abdullahi LM, Agunu A and Musa KY. Acute toxicity studies and
Hypoglycaemic activity of the methanol extract of the leaves of Hyptis suaveolens Poit. (Lamiaceae). Nigerian Journal of Pharmaceutical Sciences, 2009; 8(2): 87-92.

Garg SK. Antifertility screening of plants: Effect of four indigenous plants on early pregnancy in female albino rats. Indian Journal of Medical Research, 1976; 64(8):1133-1135.

Gentry HS, Mittleman M, McCrohan PR. Introduction of chia and gum tragacanth in the U.S. In: Janick J, Simon JE editors. Advances in new crops. Portland: Timber Press, 1990. 252-56.

Govind P. Medicinal plants against liver diseases. IJPR. 2011; 2: 115-121.

Halliwell B, Gutteridge JMC. Formation of thiobarbituric acid reactive substances from deoxyribose in the presence of iron salts: the role of superoxide and hydroxyl radicals. FEBS Lett. 1981; 128:347-352. doi: 10.1016/00145793(81)80114-7.

Kumaran, A., and Karunakaran, J.R., 2007. In-vitro antioxidant activities of methanolic extracts of five Phyllathus species from India. LWT-Food Science and Technology, 40(2): 344-352.

Lata $\mathrm{H}$, Ahuja $\mathrm{G} \mathrm{K}$, Role of free radicals in health and disease. Ind $\mathrm{J}$ physio of Allied. 2003; Okonogi S, Chansakaow $\mathrm{S}$, Vejabhikul S, Tharavichitkul P, Lerphokanont J, Nakano A and Ikegami F. Antimicrobial Activity and Pharmaceutical Development of Essential Oil from Hyptis suaveolens. Acta Hort (ISHS), 2005; 678: 163-169.

Oliver B. Medicinal plants in Nigeria. Nigeria: University of Ibadan Press, 1960. 57: 124.

Osawa T, Kavakishi S, Namiki M, Kuroda Y, Shankal DM, Waters MD. Antimutagenesis and anticarcinogenesis mechanisms II. New York: Plenum; 1990. pp. 139-153. 
Palmer E. Chia. Zoe: A Biological Journal, 1891; 2 (2): 140-142.

Ross R. The Pathogenesis of artherrosclerosis: a perspective for the 1990's. Nature. 1993; 362: 801.

Ruch, R.J., Cheng, S.J., and Klaunig, J.E., 1989. Prevention of cytotoxicity and inhibition of intercellular communication by antioxidant catechins isolated from Chinese green tea. Carcinogen, 10(6): 1003-1008.

Sainani G.S., Manika J.S. and Sainani R.G. Oxidative stress: a key factor in pathogenesis of chronic diseases. Med update.1997; 1:1.

Streejayan, N., and Rao, M.N.A., 1997. Nitric oxide scavenging by curcuminoids. Pharma. Pharmacol., 49: 105-107.
Subhashini N, Thangathirupathi A and Lavanya N. Antioxidant activity of Trigonella boenum graecum using various In vitro and Ex vivo models. I J Pharm and pharm Sciences. 2011; 3(2): 96-102.

Yildirim, A., Oktay, M., and Bilaloglu, V., 2001. The antioxidant activity of the leaves of Cydonia vulgaris. Turk. J. Med. Sci., 31: 23-27.

Ziegler H.L., Jensen T.H., Christensen J., Staerk D. and Hagerstr H. Possible Artefacts in the in vitro Determination of Antimalarial Activity of Natural Products that Incorporate into Lipid Bilayer: Apparent Antiplasmodial Activity of Dehydroabietinol, a Constituent of Hyptis suaveolens. Planta Med, 2002; 68(6): 547-9.

\section{How to cite this article:}

Mozhiyarasi, P. and Anuradha, R. 2018. A Study on Antioxidant Activity of Hyptis suaveolens (L) poit. Int.J.Curr.Microbiol.App.Sci. 7(06): 376-382. doi: https://doi.org/10.20546/ijcmas.2018.706.042 